\title{
A variação do saldo migratório internacional do Brasil
}

\author{
JOSÉ ALBERTO MAGNO DE CARVALHO \\ - MARDEN BARBOSA DE CAMPOS
}

$\mathrm{P}$ ARTE SIGNIFICATIVA dos fluxos migratórios internacionais do Brasil, tanto de imigrantes quanto de emigrantes, é constituída do que se convencionou chamar de "ilegais" ou "clandestinos". Isso impossibilita que se conheçam seus números verdadeiros por meio dos registros consulares (concessão de vistos de residência) brasileiros e estrangeiros. Pelo mesmo motivo, as informações advindas dos diversos censos demográficos do Brasil (imigrantes) e dos demais países (emigrantes) contêm, seguramente, erros por falta, cuja magnitude deve variar significativamente de país para país.
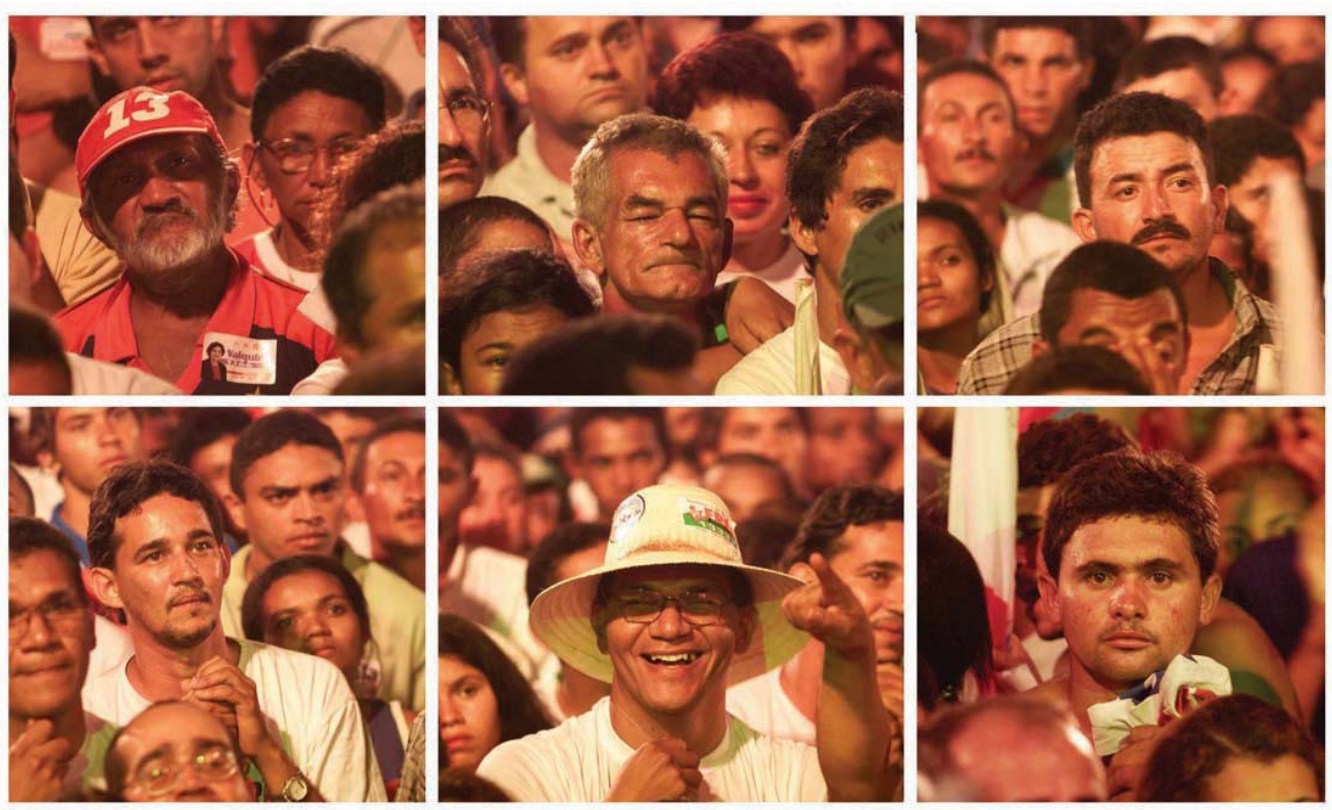

‘...] entre 1980 e 1990, um saldo migratório negativo de aproximadamente 1.800 mil pessoas.”

A partir da década de 1980, ficou cada vez mais claro que um crescente número de brasileiros passara a residir no exterior, tema que, recorrentemente, tornou-se objeto de interesse da mídia. De país historicamente grande receptor de imigrantes estrangeiros, parecia que o Brasil estava se convertendo em forte expulsor de população. No entanto, permanecia a crença (ou ilusão) de que a entrada de imigrantes estrangeiros ainda superava a saída de brasileiros. De certo modo, era doloroso para a nossa auto-estima aceitar o contrário! 
Nos anos 1990, alguns demógrafos (Oliveira et al., 1996; Carvalho, 1996) empenharam-se em estimar o saldo migratório (SM) internacional do país. Partiram de uma idéia extremamente simples: conhecendo-se as populações residentes de um país no início e no fim de um determinado período, o SM internacional seria dado pela diferença entre sua população residente e aquela esperada fechada, ambas do final do período. A população esperada fechada é estimada a partir daquela residente no início do período, submetida aos níveis observados de fecundidade e mortalidade, pressupondo-se fluxos migratórios internacionais nulos.

Carvalho (1996) chegou à conclusão de que o Brasil, entre 1980 e 1990, teria experimentado uma perda líquida de aproximadamente 1.800 mil pessoas por meio dos fluxos internacionais: 1.050 mil homens e 750 mil mulheres. Essas estimativas correspondem à média dos valores máximo e mínimo estimados pelo autor e nelas não estão incluídas as crianças nascidas durante o decênio. Portanto, referem-se a migrantes, em 1990, com dez ou mais anos de idade.

Dois pontos devem ser destacados: 1) o volume estimado de perdas surpreendeu a todos e teve forte repercussão na mídia, ainda que correspondesse a apenas 1,6\% da população de dez ou mais anos de idade, residente no país em $1990 ; 2$ ) as perdas foram preponderantemente do sexo masculino, apresentando uma razão de sexo de 1,4 .

Para estimar o SM internacional da década de 1990, teve-se que enfrentar um problema técnico suplementar, qual seja, o de melhoria expressiva da cobertura do Censo de 2000. Se não se fizesse algum tipo de ajuste, ao se comparar, em 2000, a população residente com a esperada fechada (advinda daquela enumerada de 1991), todos aqueles incluídos no Censo de 2000, como resultado de melhoria da cobertura, entrariam, implicitamente, no SM como imigrantes internacionais.

Lançou-se mão das Pesquisas de Avaliação da Cobertura da Coleta dos Censos de 1991 e 2000 (Oliveira et al., 1996; Oliveira et al., 2003), realizadas pelo IBGE, para corrigir o volume das populações recenseadas naquelas duas datas. Os novos valores correspondem, em princípio, às populações que seriam enumeradas nos dois censos, caso a cobertura censitária houvesse sido completa. A população recenseada em 1991 foi aumentada em 9,08\% e aquela em 2000, em 5,84\%.

Feitas as correções, ao se compararem as populações residente e esperada fechada em 2000, chegou-se à estimativa de um SM internacional negativo de 550 mil pessoas, correspondente à perda líquida de 294 mil homens e de 256 mil mulheres, entre aqueles com dez ou mais anos de idade em 2000.

Apesar das dificuldades técnicas para a estimação dos SM internacionais do país, o que faz que se deva considerar as estimativas com precaução, parece certo que a perda líquida populacional do Brasil durante os anos 1990 tenha sido bem menor do que aquela do decênio anterior. O descenso do SM, negativo em ambas as décadas, não significa que o número de brasileiros residentes 
no exterior tenha diminuído, mas, sim, que tenha aumentado menos do que na década de 1980.

O declínio do SM internacional negativo foi, necessariamente, conseqüência da variação, ente as duas décadas, do número de imigrantes e/ou do número de emigrantes internacionais. Em 1991 e em 2000, há um quesito que indaga o local de residência cinco anos antes da data de referência dos censos. Há, pois, entre os recenseados, informação sobre os imigrantes internacionais dos qüinqüênios 1986/1991 e 1995/2000. No Censo de 1991, 66.217 pessoas declararam que residiam no exterior havia cinco anos. No de 2000, foram 143.644 indivíduos. Houve, entre os dois qüinqüênios, um aumento pequeno, em torno de 77 mil imigrantes. Desses dados, pode-se inferir que o declínio dos SM ora estimados não pode ser explicado pelo crescimento do número de imigrantes internacionais entre as décadas de 1980 e 1990. Se aceitas as estimativas de SM internacionais apresentadas neste artigo, pode-se concluir que seu significativo decréscimo entre os dois últimos decênios se deve, fundamentalmente, à queda da emigração de brasileiros para o exterior.

O SM internacional dos anos 1980 teria correspondido a 1,6\% da população, em 1990, de dez ou mais anos de idade; dos anos 1990, teria passado para apenas $0,4 \%$. Entretanto, teria havido, nos anos 1990, um maior equilíbrio entre as perdas masculinas e femininas, com uma razão de sexo de 1,1 , contra 1,4 na década anterior. A diminuição da razão de sexo já era esperada, pois, nas primeiras fases das migrações internacionais, há, geralmente, maior prevalência de homens, tendendo, em seguida, a um maior equilíbrio, em razão, entre outras, da reunificação de famílias.

A constatação de que o fluxo de emigrantes brasileiros provavelmente tenha se reduzido, em proporção significativa, entre as duas últimas décadas não garante que o mesmo esteja ocorrendo no presente decênio. No entanto, as estimativas apresentadas oferecem, certamente, novos elementos para o debate, ora em curso no país, sobre o tema.

Referências bibliográficas

CARVALHO, J. A. M. de. O saldo dos fluxos migratórios internacionais no Brasil na década de 80: uma tentativa de estimação. In: PATARRA, N. L. (Coord.) Migrações internacionais: herança XX, agenda XXI. Campinas: FNUAP, 1996. p.227-38. (Programa interestitucional de avaliação e acompanhamento das migrações internacionais, v.2).

OLIVEIRA, A. T. R. de et al. Notas sobre a migração internacional no Brasil na década de 80. In: PATARRA, N. L. (Coord.) Migrações internacionais: herança XX, agenda XXI. Campinas: FNUAP, 1996. p.239-57. (Programa interestitucional de avaliação e acompanhamento das migrações internacionais, v.2).

OLIVEIRA, L. C. de S. et al. Avaliação da cobertura da coleta do Censo Demográfico de 1991. Rio de Janeiro: IBGE, 1996. (Texto para discussão, 84).

OLIVEIRA, L. C. de S. et al. Censo Demográfico 2000: pesquisa da cobertura da coleta, apresentação dos resultados. Rio de Janeiro: IBGE, 2003. 14lp. (Texto para discussão, 9). 
RESUMO - OS REGISTROS administrativos dos vistos consulares de residência, mesmo quando disponibilizados, tanto pelos consulados estrangeiros no Brasil quanto por aqueles do país no exterior, não permitem calcular os fluxos de imigrantes e de emigrantes internacionais, em razão da alta proporção de migrantes clandestinos ou ilegais. Como consequiência, não se pode saber, a partir dos registros, nem sequer se o Brasil tem tido saldos migratórios internacionais positivos ou negativos. Técnicas indiretas permitem estimar o saldo migratório internacional, a partir das populações enumeradas em dois censos consecutivos. Na data do segundo censo, são comparadas as populações observada (recenseada) e esperada (aquela que se teria, se porventura a população do país tivesse permanecido fechada entre os dois censos). A diferença entre elas corresponde, em princípio, ao saldo migratório internacional. Apesar das dificuldades técnicas, advindas principalmente da significativa variação de cobertura entre os Censos de $1991 \mathrm{e}$ de 2000, concluiu-se que o Brasil teria tido, entre 1980 e 1990, um saldo migratório negativo de aproximadamente 1.800 mil pessoas. O saldo, também negativo, teria caído significativamente, no decênio 1990/2000, para em torno de 550 mil pessoas. Esse declínio teria ocorrido em razão, quase que inteiramente, da diminuição da emigração brasileira. A imigração internacional aumentou muito pouco, como se pode constatar a partir dos dados censitários de 1991 e 2000.

PALAVRAS-CHAVE: População, Migração internacional.

ABSTRACT - ADMINISTRATIVE records from consular representations in Brazil and abroad are not adequate to estimate international migration balance (the difference between inmigration and emigration) for two main reasons. First, such data are not always available. Second, even if available, these data are not reliable sources of internatonal migration flows due to underestimation of illegal migration. Thus, it is not possible to use these records to unveil the magnitude and direction of Brazil's international migration balance. Indirect techniques allows estimating international migration balance from two consecutive censuses. These techniques involve comparing the population in the second census (the "observed population") and an "expected population", which is an estimation of the closed population in the second census (that is, the expected population in the second census assuming absence of international migration - emigration and inmigration - between the two censuses). The difference between the observed and the closed population is a proxy of the international migration balance. Even considering problems in these estmations, notably the variability in census coverage rates between 1980 and 1991, it can be inferred that Brazil had a negative migraton balance (or alternatively, a higher number of emigrants compared to inmigrants) of about 1.8 million people. The balance, still negative, felt to about 550,000 people between 1990-2000. This decline can be attributed almost entirely to the decline in Brazilian emigration. The 1991 and 2000 censuses reveal a very small increase in Brazilian international inmigration.

KEXWORDS: Population, International Migration.

José Alberto Magno de Carvalho é professor do Departamento de Demografia e Cedeplar/FACE da UFMG e bolsista do CNPq. @ - carvalho@cedeplar.ufmg.br

Marden Barbosa de Campos é doutorando no Departamento de Demografia do Cedeplar/FACE da UFMG e analista socioeconômico do IBGE.

@ - marden@cedeplar.ufmg.br

Recebido em 24.5.2006 e aceito em 26.5.2006. 